\title{
In Vitro Propagation of HS314 Rootstock (Prunus amygdalus $\times$ \\ P. persica)
}

\author{
Jalil Dejampour
}

Sahand Horticultural Research Station, P.O. Box 53555-141, Tabriz, Iran

Islam Majidi

Agricultural Biotechnology Research Institute, P.O. Box 31535-1897, Karaj, Iran

\section{Solmaz Khosravi ${ }^{1}$ and Sevil Farhadi}

Department of Tissue Culture, West and West-North Branch of Agricultural Biotechnology Research Institute, 29 bahban St., P.O. Box 5156915-598, Tabriz, Iran

\author{
Atena Shadmehr \\ Faculty of Agriculture, PayamNoor University, P.O. Box 31535-3413, Karaj, \\ Iran
}

Additional index words. BAP, DKW, IBA, proliferation, Prunus

\begin{abstract}
A micropropagation protocol was developed for the HS314 rootstock, a hybrid between almond and peach that could be used as an alternative rootstock instead of GF677. Surface-sterilized nodal segments were cultured in a modified DKW medium containing $3 \%$ sucrose, $100 \mathrm{mg} \cdot \mathrm{L}^{-1}$ of Phloroglucinol, $0.7 \%$ plant agar, and $0.5 \mathrm{mg} \cdot \mathrm{L}^{-1}$ benzyl amino purine (BAP). Explants were transferred to the same culture media supplemented with $0.5,1$, or $2 \mathrm{mg} \cdot \mathrm{L}^{-1}$ BAP and $0,0.1$, or $0.5 \mathrm{mg} \cdot \mathrm{L}^{-1}$ indole butyric acid (IBA) for further shoot proliferation. The maximum number of shoots produced on a medium containing $2 \mathrm{mg} \cdot \mathrm{L}^{-1}$ BAP. Microshoots were transferred to the DKW medium supplemented with $0.5,1,2$, or $4 \mathrm{mg} \cdot \mathrm{L}^{-1}$ IBA or naphthaleneacetic acid (NAA) for root induction. The highest root number and the greatest root length were gained on a medium containing $2 \mathrm{mg} \cdot \mathrm{L}^{-1}$ IBA. Rooting percentage was improved from $66 \%$ to more than $85 \%$ by reducing the concentration of DKW salts to half strength. Finally, rooted plantlets were successfully acclimatized and transferred in vivo conditions.
\end{abstract}

According to the FAO (2008), Iran is second, third, and sixth in global ranking of apricot, almond, peach and nectarine production, respectively. Almost 158,675 ha of plantations in Azerbaijan province (Iran) are allocated to various stone fruits such as almond, peach, nectarine, apricot, etc. (Ministry of Agriculture of Iran, 2007). Despite the economic importance of these orchards, there are very few drought-tolerant rootstocks suitable for grafting the new improved varieties. Therefore, more than $50 \%$ of the groves are threatened by drought conditions. Similarly, there are lots of places suffering drought conditions. Thereupon, producing desirable numbers of a new hybrid rootstock that have

Received for publication 30 Nov. 2010. Accepted for publication 11 Mar. 2011.

This project was carried out with financial support from the Agricultural Biotechnology Research Institute, Tabriz, Iran.

We are grateful to Dr. Narges Mojtahedi for her statistical advice and Dr. Ali Vatanpour Azghandi and Dr. Maryam jafarkhni kermani for revision of the article.

${ }^{1}$ To whom reprint requests should be addressed; e-mail S_kh22@yahoo.com. was conducted to develop an efficient protocol for in vitro propagation of the HS314 rootstock that may be suitable as a rootstock for stone fruits in drought-impacted environments.

\section{Materials and Methods}

Plant material. Shoots of HS314 rootstock were obtained in June from the Sahand Horticultural Research Station, Tabriz, Iran. Nodal segments of 0.5 to $1 \mathrm{~cm}$ lengths, including axillary buds, were used as explants.

Establishment and proliferation of HS314 rootstock shoots in vitro. Explants were surface-sterilized by immersing them in $70 \%$ (v/ v) ethanol for $1 \mathrm{~min}$ followed by $50 \%(\mathrm{v} / \mathrm{v})$ bleach $[2.5 \%(\mathrm{v} / \mathrm{v})$ sodium hypochlorite solution] plus 2 drops of Tween- 80 for $10 \mathrm{~min}$ and rinsing four times with sterile-distilled water. Explants were placed on a modified DKW medium (Driver and Kuniyuki, 1984) supplemented with $3 \%(\mathrm{w} / \mathrm{v})$ sucrose, $100 \mathrm{mg} \cdot \mathrm{L}^{-1}$ of Phloroglucinol, $0.7 \%$ (w/v) plant agar (Duchefa Co., The Netherlands), and $0.5 \mathrm{mg} \cdot \mathrm{L}^{-1} \mathrm{BAP}$. The $\mathrm{pH}$ was adjusted to the value of 5.7. All media were autoclaved at $121^{\circ} \mathrm{C}$ for $15 \mathrm{~min}$. The in vitro-established explants were transferred to the same culture media containing different kinds of plant growth regulators for further proliferation (Table 1). All cultures were maintained under a 16-h light condition (supplied by fluorescent lamps) with 48 $\mu \mathrm{mol} \cdot \mathrm{m}^{-2} \cdot \mathrm{s}^{-1}$ intensity and subsequent $8-\mathrm{h}$ dark condition in a growth chamber at $23 \pm 1$ ${ }^{\circ} \mathrm{C}$. They were sub-cultured every 3 weeks.

Rooting and acclimatization. For rooting, 2 to $3 \mathrm{~cm}$ long microshoots were cultured in DKW medium containing half-strength of macroelements plus IBA (Table 2) or NAA (similar concentrations to IBA) for 1 week in the dark. Shoots were transferred to a hormonefree DKW for root development in light conditions. To improve rooting, the effects of different concentrations of macro- and microelements of DKW medium plus two levels of IBA were studied (Table 3). For acclimatization, rooted plantlets were washed with tap water to remove any residual agar and were transplanted into disposable plastic pots containing peatmoss soil ticultural Research Station of Tabriz is an appropriate alternative for GF677 and has shown a better tolerance to saline conditions in comparison with GF677 (Dejampour et al., 2009). To produce the required number of HS314 plants, a suitable propagation method is necessary.

Micropropagation is a suitable and fast method for obtaining a large number of genetically identical plants (Antonopoulou et al., 2005). Micropropagation techniques for Prunus species like apricot (Koubouris and Vasilakakis, 2006; Marino et al., 1993; PerezTornero et al., 1999), cherries (Pedrotti et al., 1993; Sedlák and Paprštein, 2008; Tang et al., 2001), almond (Ainsley et al., 2001a, 2001b; Channuntapipat et al., 2003; Gurel and Gulsen, 1998; Islkalan et al., 2008), and some Prunus interspecific hybrid rootstocks like PR 204/84 (Fotopoulos and Sotiropoulos, 2005), GF677 (Kamali et al., 2006), PeMa (Balla and Kirilla, 2006) have been described. The present study
Table 1. Proliferation treatments containing different concentrations of benzyl amino purine (BAP) and indole butyric acid (IBA) for the HS314 rootstock explants. $^{\mathrm{z}}$

\begin{tabular}{lccc}
\hline & \multicolumn{3}{c}{$\mathrm{BAP}\left(\mathrm{mg} \cdot \mathrm{L}^{-1}\right)$} \\
\cline { 2 - 4 } IBA $\left(\mathrm{mg} \cdot \mathrm{L}^{-1}\right)$ & 0.5 & 1 & 2 \\
\hline 0 & P1 & P2 & P3 \\
0.1 & P4 & P5 & P6 \\
0.5 & P7 & P8 & P9 \\
\hline
\end{tabular}

${ }^{\mathrm{z}}$ Each combination of special IBA level and BAP are named as $\mathrm{P} 1-\mathrm{P} 9$.

Table 2. Rooting induction treatments including various indole butyric acid (IBA) concentrations for the HS314 rootstock explants. ${ }^{\mathrm{Z}}$

\begin{tabular}{lccccc}
\hline & \multicolumn{5}{c}{ IBA $\left(\mathrm{mg} \cdot \mathrm{L}^{-1}\right)$} \\
\cline { 2 - 6 } & 0 & 0.5 & 1 & 2 & 4 \\
\hline Rooting media & $0 \mathrm{R}$ & $1 \mathrm{R}$ & $2 \mathrm{R}$ & $3 \mathrm{R}$ & $4 \mathrm{R}$ \\
\hline
\end{tabular}

${ }^{ }$Each special IBA level is named as $0 \mathrm{R}-4 \mathrm{R}$. 
Table 3. Different indole butyric acid (IBA) concentrations in combination with various salt concentration of DKW medium to improve rooting rate of HS314 rootstock explants, which are named as $5 R-10 R$.

\begin{tabular}{lcr}
\hline & \multicolumn{2}{c}{ IBA $\left(\mathrm{mg} \cdot \mathrm{L}^{-1}\right)$} \\
\cline { 2 - 3 } DKW salt concn & 2 & 3 \\
\hline $1 / 2$ macroelements & $5 \mathrm{R}$ & $6 \mathrm{R}$ \\
$1 / 2 \mathrm{DKW}$ & $7 \mathrm{R}$ & $8 \mathrm{R}$ \\
DKW & $9 \mathrm{R}$ & $10 \mathrm{R}$ \\
\hline
\end{tabular}

and perlite (1:3) and covered with small transparent plastic covers. After 2 weeks, a few small holes were drilled for aeration. The coverings were removed completely after 1 month. Every 2 weeks, the plantlets were fertilized with $0.1 \%$ $(\mathrm{w} / \mathrm{v}) \mathrm{N}: \mathrm{P}: \mathrm{K}$ solution $(1: 1: 1)$.

Statistical analysis. The data from each experiment were analyzed based on simple (Table 2) and factorial completely randomized design (Tables 1 and 3 ) using the GLM method of SAS system (Release 6.12; SAS Institute Inc., Cary, NC). Means were separated by the Duncan's multiple range test (Duncan, 1995). Each experiment had five replicates that were repeated twice. Because the data did not follow a normal distribution, the number of both regenerated shoots and roots were transformed by $\mathrm{y}=\sqrt{\mathrm{x}}+0.5$ before analysis.

\section{Results}

The establishment of nodal explants in vitro occurred 3 to 4 weeks after being placed in the culture medium. After 6 weeks, the height of regenerated shoots reached 1 to $2 \mathrm{~cm}$ and were suitable for transfer to proliferation media (Fig. 1A). New shoots were proliferated in the P1-P9 media after 1 month (Fig. 1B). Proliferation rate was proportional to BAP level with a significant difference observed between BAP levels $(P \leq 0.05)$. As BAP concentrations in the culture media increased, the number of axillary shoots/ explants also increased. The highest proliferation rate was recorded in the P3 medium containing $2 \mathrm{mg} \cdot \mathrm{L}^{-1} \mathrm{BAP}$ with an average of three adventitious shoots/explants (Fig. 2). Neither IBA nor its interaction with BAP was found to have a significant impact concerning proliferation.

For rooting, it was found that NAA was not capable of inducing root formation (data not shown). Roots were however formed on media containing various concentration of IBA (Fig. 1C). Statistical differences in IBA levels $(P \leq 0.05)$ indicated that the root number and root length increased as IBA concentration was increased (Fig. 3). Highest root numbers and root lengths were observed in the $3 \mathrm{R}\left(2 \mathrm{mg} \cdot \mathrm{L}^{-1} \mathrm{IBA}\right)$ and $4 \mathrm{R}\left(4 \mathrm{mg} \cdot \mathrm{L}^{-1}\right.$ IBA) media. Although root production in $3 R$ and $4 R$ media was similar, rooted explants from $4 \mathrm{R}$ medium displayed severe leaf abscission (Fig. 1D).

Comparing different concentrations of DKW salts showed reducing DKW salts to half strength was significantly effective in improving rooting percentage. The highest percentage $(85 \%)$ of rooting was obtained in
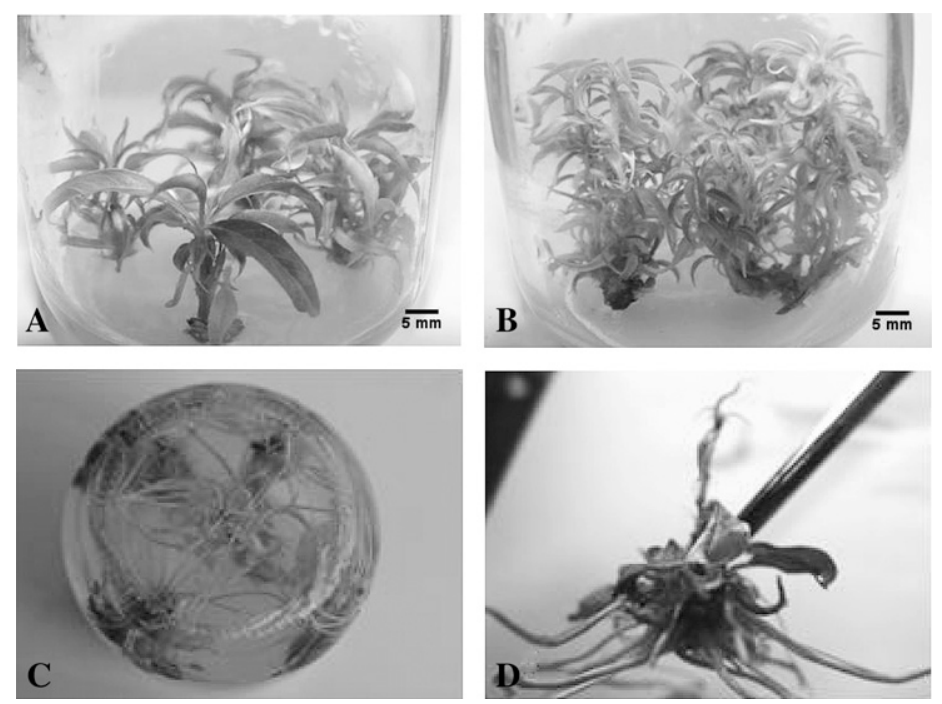

Fig. 1. (A) Establishment of nodal explants of the HS314 in DKW after 6 weeks. (B) Shoot proliferation in P3 medium containing $2 \mathrm{mg} \cdot \mathrm{L}^{-1}$ benzyl amino purine (BAP) after 1 month. (C) Root induction in 3R medium containing $2 \mathrm{mg} \cdot \mathrm{L}^{-1}$ indole butyric acid (IBA) after 1 month. (D) Leaf abscission of an explant after being treated in $4 \mathrm{R}$ medium. Scale bar on $\mathbf{A}$ and $\mathbf{B}$ is equivalent to $5 \mathrm{~mm}$.

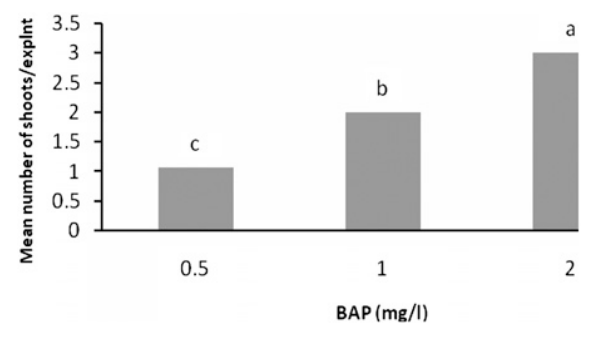

Fig. 2. Number of axillary shoots/explant in proliferating media after 1 month. Medium containing $2 \mathrm{mg} \cdot \mathrm{L}^{-1}$ benzyl amino purine (BAP) caused more shoots/explants. Different letter(s) indicate significant differences at $P \leq 0.01$ by Duncan's multiple range test.

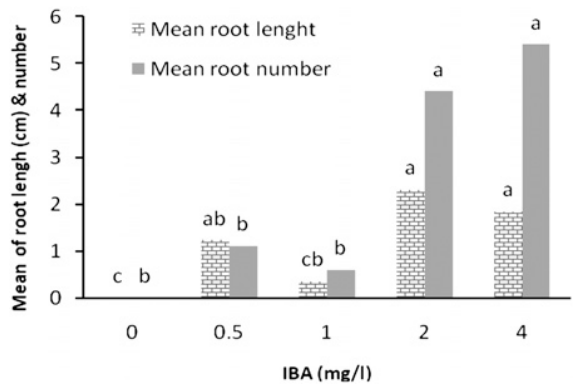

Fig. 3. Number and length of roots in root induction media after 1 month. As indole butyric acid (IBA) level rises, root length and number increase. Different letter(s) indicate significant differences at $P \leq 0.05$ by Duncan's multiple range test.

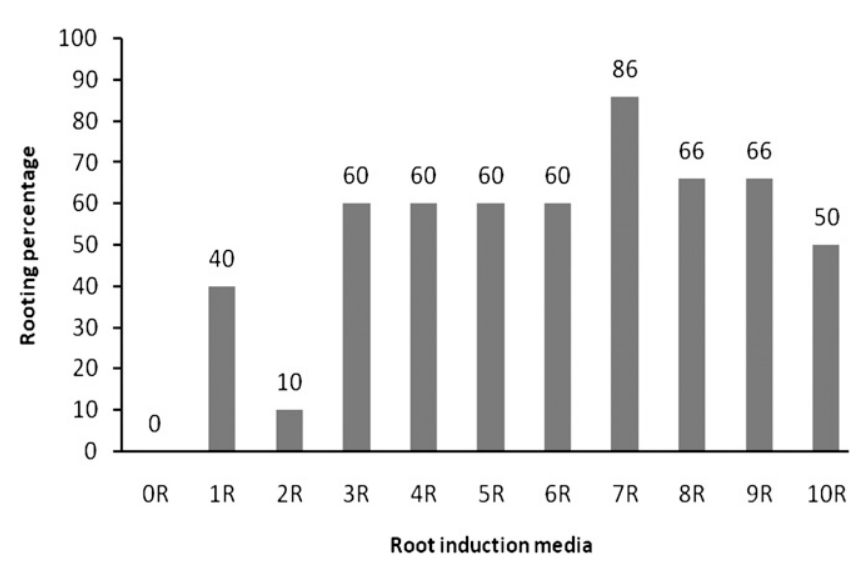

Fig. 4. Comparison of root induction percentage in all applied rooting treatments after 1 month. The highest rooting percentage gained through $7 \mathrm{R}$ medium $\left(1 / 2 \mathrm{DKW}+2 \mathrm{mg} \cdot \mathrm{L}^{-1}\right.$ indole butyric acid).

7R medium $\left(1 / 2 \mathrm{DKW}+2 \mathrm{mg} \cdot \mathrm{L}^{-1} \mathrm{IBA}\right)$ (Fig. 4). However, root number and root length were not significantly affected by modifying the concentration of DKW salts (Fig. 5).
Rooted plantlets were transferred in vivo for acclimatization (Fig. 6A). The survival rate during acclimatization was $85 \%$. Welladapted plantlets from the greenhouse once 
attaining a height of $1 \mathrm{~m}$ were successfully transferred to the orchard (Fig. 6B).

\section{Discussion}

Explants were successfully established in DKW medium containing $0.5 \mathrm{mg} \cdot \mathrm{L}^{-1} \mathrm{BAP}$. The DKW has been used for tissue culture of sour cherry (Prunus cerasus L.) by Tang et al. (2001). Shoot proliferation was also best in the same medium supplemented with $2 \mathrm{mg} \cdot \mathrm{L}^{-1} \mathrm{BAP}$, which is known as a suitable cytokinin for proliferation of Prunus species (Channuntapipat et al., 2003; Kalinina and Brown, 2007; Koubouris and Vasilakakis, 2006). As presented in this report, $2 \mathrm{mg} \cdot \mathrm{L}^{-1}$ BAP was suitable for proliferation of HS314, which is in accordance with Channuntapipat et al. (2003). In contrast, Kalinina and Brown (2007) reported multiple shoot formation in the different species of ornamental Prunus spp. and the GF305 peach rootstock meristem culture by using $1 \mathrm{mg} \cdot \mathrm{L}^{-1}$ BAP in Murashige and Skoog (MS) medium (Murashige and

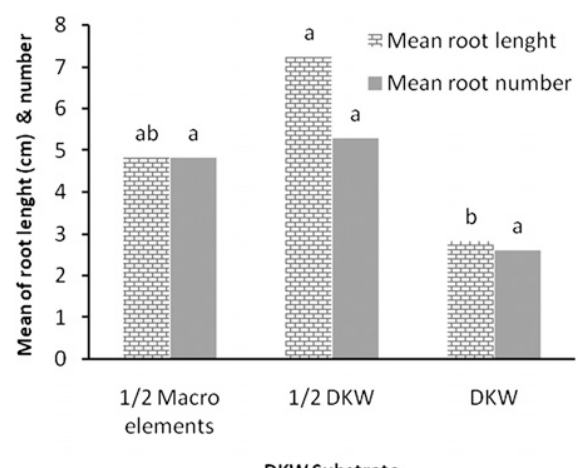

Fig. 5. Effect of DKW salt concentrations on root induction after 1 month. It affected just root length. Medium containing half of macro- and microelements of DKW caused highest root length. Different letter(s) indicate significant differences at $P \leq 0.05$ by Duncan's multiple range test.
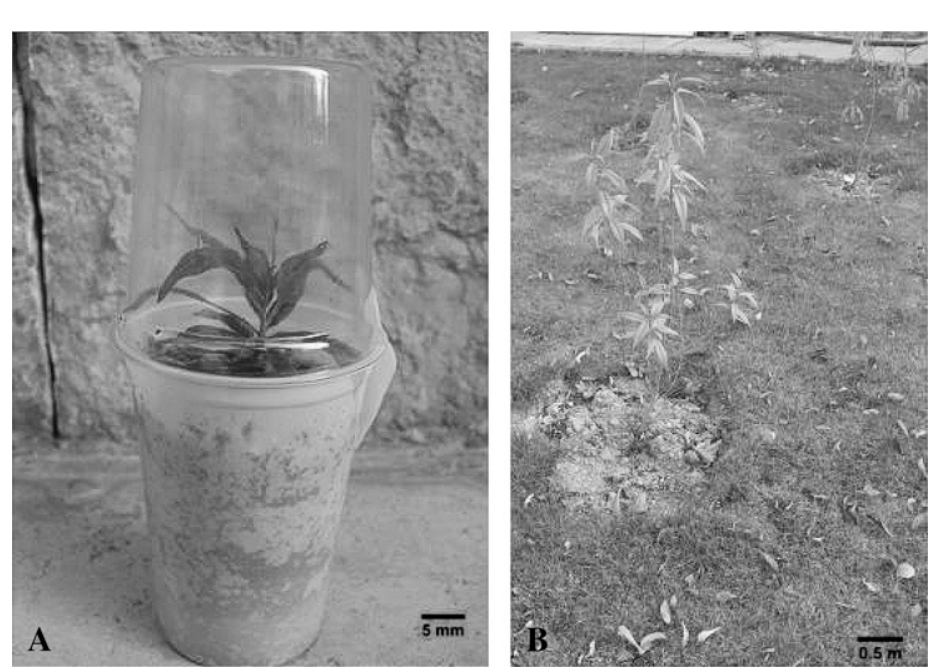

Fig. 6. (A) Transferring of plantlets to plastic pots for acclimatization. (B) Survived plantlets grown in an orchard. Scale bars on $\mathbf{A}$ and $\mathbf{B}$ are equivalent to $5 \mathrm{~mm}$ and $0.5 \mathrm{~m}$, respectively.

Skoog, 1962). The proliferation rate reported by these researchers varied from $50 \%$ to $100 \%$ depending on the genotype. The differences observed between Kalinina and Brown's results and ours might be the result of genotype effect.

IBA did not exert a significant effect on proliferation rate in our work. Ainsley et al. (2001a) suggested that IBA reduced the development of adventitious shoots significantly. The difference may be ascribed to the internal auxin content of HS314 explants, which is sufficient to balance the auxin and cytokinin concentrations within the plant so they can proliferate better in IBA-free media.

Root induction was achieved by treating explants in $2 \mathrm{mg} \cdot \mathrm{L}^{-1}$ IBA with incubating them for $7 \mathrm{~d}$ in the dark followed by culture for 3 weeks in IBA-free medium in the light. IBA has been used for root induction in many Prunus spp. Kalinina and Brown (2007) achieved root induction using a two-step protocol, $4 \mathrm{~d}$ root induction in IBA containing medium $\left(3 \mathrm{mg} \cdot \mathrm{L}^{-1}\right)$ followed by 3 weeks root elongation in IBA-free medium. The positive effect of light exclusion on rooting has been explained by increasing of endogenous auxin and rooting factor level (Maynard and Bassuk, 1987). However, Davis and Haissig (1993) correlated the effect of etiolation to the ability of cells in the expressing genes that are required for rooting.

Depending on Prunus genotype, culture medium used by Kalinia and Brown varied from MS to half-strength MS. Fotopoulos and Sotiropoulos (2005) reported that increasing IBA levels raised root number in both full- and half-strength MS media but root length was unaffected. According to them, reducing the mineral concentration of MS medium to half-strength increased rooting percentage. Also Tang et al. (2001) used half-strength MS medium containing $2 \mathrm{mg} \cdot \mathrm{L}^{-1}$ IBA or NAA with or without an initial darkness treatment for rooting of Prunus avium L. and Prunus cerasus L. The constructive impact of diluted mineral concentration of culture medium on rooting can be attributed to the reduction of nitrogen concentration (Driver and Suttle, 1987; Sriskandarajah et al., 1990). The results obtained in the present investigation also showed that using halfstrength medium improved the percentage of rooted plantlets from $66 \%$ to more than $85 \%$.

Findings in the current research indicate that using $2 \mathrm{mg} \cdot \mathrm{L}^{-1} \mathrm{BAP}$ for proliferation and $2 \mathrm{mg} \cdot \mathrm{L}^{-1}$ IBA for rooting is necessary for in vitro micropropagation of the HS314 rootstock. This is the first report of using micropropagation for this rootstock.

\section{Literature Cited}

Ainsley, P.J., F.A. Hammerschlag, T. Bertozzi, G.G. Collins, and M. Sedgley. 2001a. Regeneration of almond from immature seed cotyledons. Plant Cell Tissue Organ Cult. 67:221-226.

Ainsley, P.J., G.G. Collins, and M. Sedgley. 2001b. In vitro rooting of almond (Prunus dulcis Mill.). In Vitro Cell. Dev. Biol. Plant 37:778-785.

Antonopoulou, Ch., K. Dimassi, I. Therios., Ch. Chatzissavvidis, and V. Tsirakoglou. 2005. Inhibitory effects of riboflavin (Vitamin B2) on the in vitro rooting and nutrient concentration of explants of peach rootstock GF 677 (Prunus amygdalus $\times$ P. persica). Sci. Hort. 106:268-272.

Balla, I. and Z. Kirilla. 2006. Micropropagation of peach rootstocks and cultivars. Acta Hort. 725: 511-516.

Channuntapipat, Ch., M. Sedgley, and G. Collins. 2003. Micropropagation of almond cultivars Nonpareil and Ne Plus Ultra and the hybrid rootstock Titan $\times$ Nemaguard. Scientia Horticulturae 98:473-484.

Davis, D. and E.B. Haissig. 1993. Biology of adventitious root formation. Basic Life Sci. 52:102.

Dejampour, J., N. Aliasgarzad, V. Grigorian, and E. Majidi. 2009. Effects of salts mixture salinity on leaf proline, chlorophyll and growth of some interspecific hybrids and almond (prunus amygdalus B.). 5th International Symposium on Pistachios and Almond-ISHS, Turkey. p. 33.

Dejampour, J., H. Rahnemonn, and D. Hassani. 2005. Breeding almond interspecific hybrid rootstocks in Iran. Acta Hort. 726:45-50.

Driver, J.A. and G.R. Suttle. 1987. Nursery handling of propagles, p. 320-335. In: Bonga, J.M. and D.J. Durzan (eds.). Cell and tissue culture in forestry. Martinus Nijhoff Publishers, Dortrecht, The Netherlands.

Driver, J.H. and A.H. Kuniyuki. 1984. In vitro propagation of Paradox walnut rootstock. HortScience 19:507-509.

Duncan, D.B. 1995. Multiple range and multiple F tests. Biometrics 11:1-42.

FAO. 2008. Food and agriculture commodities production. 3 Jan. 2010. $<$ http://faostat.fao.org/ site/339/default.aspx $>$.

Fotopoulos, S. and T.E. Sotiropoulos. 2005. In vitro rooting of PR 204/84 rootstock (Prunus persica $\times P$. amygdalus) as influenced by mineral concentration of the culture medium and exposure to darkness for period. Agronomy Research 3:3-8.

Gurel, S. and Y. Gulsen. 1998. Effects of IBA and BAP on in vitro shoot production of almond (Amygdalus communis L.). Tr. J. Botany 22: 375-379.

Isıkalan, C., F. Adıyaman Akbas, S. Namlı, E. Tilkat, and D. Basaran. 2008. In vitro micropropagation of almond (Amygdalus communis L. cv. Nonpareil). Afr. J. Biotechnol. 7:1875-1880.

Kalinina, A. and D. Brown. 2007. Micropropagation of ornamental Prunus spp. and GF305 
peach, a Prunus viral indicator. Plant Cell Rep. 26:927-935.

Kamali, K., E. Majidi, R. Zarghami, and M.J. Arvin. 2006. Differences in micropropagation of vegetative rootstock (GF677) and other almond seed genotypes. Acta Hort. 726:199-200.

Koubouris, G. and M. Vasilakakis. 2006. Improvement of in vitro propagation of apricot cultivar 'Bebecou'. Plant Cell Tissue Organ Cult. 85: 173-180.

Marino, M., G. Bertazza, E. Magnanini, and A. Doro Altan. 1993. Comparative effects of sorbitol and sucrose as main carbon energy sources in micropropagation of apricot. Plant Cell Tissue Organ Cult. 34:235-244.
Maynard, K.B. and N.L. Bassuk. 1987. Etiolation and banding effects on adventitious root formation. In: Davies, T., B.E. Haising, and N. Sankhla (eds.). Adventitious root formation. Dioscourides Press, Portland, OR.

Ministry of Agriculture of Iran. 2007. <http://ww. maj.ir>.

Murashige, T. and F. Skoog. 1962. A revised medium for rapid growth and bioassays with tobacco tissue culture. Phisyol Plant 15:473497.

Pedrotti, E.L., C. Jey-Allemand, P. Doumas, and D. Cornu. 1993. Effect of autoclaving amino acids on in vitro rooting response of wild cherry shoot. Sci. Hort. 57:81-98.
Perez-Tornero, D., J. Egea, A. Vanoostende, and L. Burgos. 1999. Assessment of factors affecting adventitious regeneration from in vitro cultured leaves of apricot. Plant Sci. 158:61-70.

Sedlák, J. and F. Paprštein. 2008. In vitro shoot proliferation of sweet cherry cultivars Karešova and Rivan. Hort. Sci. (Prague) 353:95-98.

Sriskandarajah, S., R.M. Skirvin, and H. AbuQaoud. 1990. The effect of some macronutrients on adventitious root development on scion apple cultivars in vitro. Plant Cell Tissue Organ Cult. 21:185-189.

Tang, H., Z. Ren, G. Reustle, and G. Krczal. 2001. Plant regeneration from leaves of sweet and sour cherry cultivars. Sci. Hort. 93:235-244. 